\title{
Pengaruh Model Problem Based Learning Berbasis Multimedia Terhadap Kemampuan Berpikir Kritis dan Hasil Belajar IPA
}

\author{
Tri Wulandari ${ }^{1}$; Abdul Kadir ${ }^{2}$; Jumarddin La Fua²; Zainuddin ${ }^{2}$ \\ $\left.{ }^{1}\right)$ Alumni Prodi Tadris IPA, Fakultas Tarbiyah dan Ilmu Keguruan (FTIK), Institut Agama Islam Negeri (IAIN) \\ Kendari; \\ ${ }^{2)}$ Dosen FTIK, IAIN Kendari \\ Email Korespondensi : abdul.kadir.libukang@gmail.com
}

\begin{abstract}
This article was a quantitative study aimed to find out: Differences in students' critical thinking skills and student learning outcomes using PBL models based on multimedia and conventional learning models. This research is an experimental research with posttest only control group design used in students of class VIII of SMP Negeri 2 Abuki in the 2018/2019 academic year. Data collection techniques in this study used test instruments, questionnaires and documentation. The instrument validity test uses the Product Moment formula and the reliability test uses the Cronbach Alpha formula, with the prerequisite test analysis using the normality test and homogeneity test. Data analysis techniques used include the first hypothesis test and the second hypothesis using the average test (t-test). The results showed that: There were differences in students' critical thinking skills using multimedia-based PBL models and those using conventional models (thit 9.9> ttab 1.67). And there are differences in student learning outcomes using multimedia-based PBL models and those using conventional models (thit 10.2>1.67 tab).
\end{abstract}

Keywords: Problem Based Learning, critical thinking skills, learning outcomes

\begin{abstract}
ABSTRAK
Artikel ini adalah penelitian kuantitatif bertujuan untuk mengetahui: Perbedaan kemampuan berpikir kritis siswa dan hasil belajar siswa yang menggunakan model PBL berbasis multimedia dan model pembelajaran konvensional. Penelitian ini merupakan penelitian eksperimen dengan desain posttest only control group design yang digunakan pada siswa kelas VIII SMP Negeri 2 Abuki tahun pelajaran 2018/2019. Teknik pengumpulan data pada penelitian ini menggunakan instrumen tes, angket dan dokumentasi. Uji validitas instrumen menggunakan rumus Product Moment dan uji reliabilitas menggunakan rumus Cronbach Alpha, dengan uji prasyarat analisis menggunakan uji normalitas dan uji homogenitas. Teknik analisis data yang digunakan meliputi uji hipotesis pertama dan hipotesis kedua dengan menggunakan uji rerata (uji $t$-test). Hasil penelitian menunjukkan bahwa: Terdapat perbedaan kemampuan berpikir kritis siswa yang menggunakan model PBL berasis multimedia dan yang menggunakan model konvensional ( $\left.t_{h i t} 9,9>t_{t a b} 1,67\right)$. Serta terdapat perbedaan hasil belajar siswa yang menggunakan model PBL berasis multimedia dan yang menggunakan model konvensional $\left(t_{\text {hit }} 10,2>t_{\text {tab }} 1,67\right)$.
\end{abstract}

Kata Kunci: Problem Based Learning, Kemampuan Berpikir Kritis, Hasil Belajar

\section{PENDAHULUAN}

Pendidikan merupakan usaha sadar dan terencana untuk mewujudkan suasana belajar dan proses pembelajaran yang menyenangkan agar peserta didik secara aktif mengembangkan potensi dirinya untuk memiliki kekuatan spiritual keagamaan, pengendalian diri, kepribadian, kecerdasan, ahlak mulia, serta keterampilan yang diperlukan dirinya, masyarakat, bangsa dan negara. Pembelajaran Ilmu Pengetahuan Alam (IPA) di Sekolah Menengah Pertama (SMP) mencakup tiga aspek, yaitu aspek biologi, fisika, dan kimia yang dikaji secara utuh. Pelajaran IPA di sekolah masih menjadi pelajaran yang dianggap sulit bagi sebagian siswa, khususnya siswa SMP. Pelajaran IPA juga dianggap membosankan karena hanya bisa dikerjakan oleh siswa yang pintar, kemudian guru yang hanya memberikan materi berupa rumus-rumus dan membuat siswa kesulitan dalam memahami pelajaran IPA. Metode yang terlalu sering dipakai guru tanpa banyak melihat kemungkinan penerapan metode lain sesuai dengan jenis materi dan bahan serta alat yang tersedia (Astuti, dkk., 2015). Oleh sebab itu, guru seharusnya memberikan sajian materi IPA dengan mudah dan menyenangkan agar dapat diterima oleh siswa dengan berbagai kemampuan. Model pembelajaran yang digunakan terlalu sering juga dapat membuat siswa menjadi bosan dan pasif, itu semua sangat bertentangan dengan sains yang dimana siswa dituntut aktif dalam belajar maupun melakukan kegiatan praktikum.

Mata pelajaran IPA di SMP Negeri 2 Abuki masih dianggap sangat sulit oleh sebagian siswa. Hal tersebut dapat dilihat dari nilai Kriteria Ketuntasan minimum (KKM) siswa kelas VIII pada mata pelajaran IPA 
masih dibawah standar yaitu dengan nilai rata-rata mata pelajaran IPA 71,6 dari nilai KKM yaitu 73. Agar hasil belajar IPA menjadi lebih baik, guru dapat menghadirkan kegiatan pembelajaran yang inovatif dan menyenangkan diantaranya dengan menerapkan model PBL (Problem Based Learning) melalui kerja kelompok berbasis masalah serta merupakan wahana untuk melatih kepekaan penilaian siswa terhadap lingkungan sebagai akibat perkembangan sains dan teknologi (Poedjiadji, 2010). Media pembelajaran sangat berperan penting dalam proses belajar mengajar guna untuk tercapainya tujuan pembelajaran. Menurut Undang-Undang Sisdiknas NO. 20 Tahun 2003 Pasal 40 ; 2, Pendidik dan tenaga kependidikan berkewajiban menciptakan suasana pendidikan yang bermakna, menyenangkan, kreatif, dinamis dan idealogis (Bidang DIKBUD, 2013). Untuk menerapkan apa yang tertulis dalam Undang-Undang Sisdiknas dalam pembelajaran, guru tidak bisa mengajar hanya dengan menggunakan satu metode yang sama setiap harinya karena, hal tersebut dapat membuat siswa merasa bosan. Pemanfaatan media pembalajaran diharapkan dapat memperbaiki kualitas pembelajaran yang awalnya sangat monoton dengan salah satu metode dalam pendekatan saitifik dan model pembelajaran yang sangat sederhana dan biasa saja, saat ini media pembelajaran sudah harus di masukkan ke dalam berbagai model pembelajaran atau dikombinasikan sehingga dapat menjadi penunjang semua metode yang digunakan dalam proses pembelajaran.

\section{METODE PENELITIAN}

Jenis penelitian ini adalah penelitian kuantitatif dengan menggunakan metode penelitian eksperiman yang rancangannya adalah Posttest Control Group Design. Populasi penelitian ini adalah peserta didik kelas VIII semester genap tahun pelajaran 2018/2019. Sampel dipilih dengan teknik purposive sampling yaitu memilih dengan pertimbanan tertentu dan menetapkan kelas VIII A sebagai kelas eksperimen dan kelas VIII B sebagai kelas kontrol. Instrumen yang digunakan dalam penelitian ini adalah tes pengetahuan dan tes kemampuan berpikir kritis yang telah diuji validitas dan reliabilitasnya. Sedangkan teknik analisis data yang digunakan dalam penelitian ini adalah analisis statistika deskriptif dan stastika inferensial.

Analisis statistika deskriptif, yaitu menghitung rata-rata, median, modus, standar deviasi, variansi, distribusi frekuensi, persentse dan kategori. Sedangkan analisis statistika inferensial diawali dengan melakukan uji persyaratan analisis, yaitu; uji normalitas Lillifors test dan uji homogenitas; Uji $F$, selanjutnya untuk pengujian hipitesis digunakan $T$-test dengan membandingkan nilai $\mathrm{t}_{\text {hitung }}$ dan $\mathrm{t}_{\text {tabel }}$ dengan taraf signifikansi $\mathrm{a}=$ 0,05. Selanjutnya melakukan interpretasi data dari hasil-hasil pengujian tersebut kemudian menarik kesimpulan dari hasil penelitian.

\section{HASIL PENELITIAN}

\section{Nilai Kemampuan Berpikir Kritis dan Hasil Belajar}

Data hasil penelitian tentang tingkat pengetahuan dan sikap perserta didik yang diperoleh melalui penerapan model PBL berbasis multimedia dan konvensional, diukur dengan intrumen tes kemampua berpikir kritis dan hasil belajar, diolah dan dianalisis secara deskriptif sebagaimana disajikan pada tabel berikut:

Tabel 1. Nilai Kemampuan Berpikir Kritis dan Hasil Belajar Peserta Didik

\begin{tabular}{|c|c|c|c|c|}
\hline \multirow{2}{*}{ Statistik } & \multicolumn{2}{|c|}{ Nilai Kemampuan Berpikir Kritis dan Hasil Belajar Peserta Didik } \\
\cline { 2 - 5 } & \multicolumn{2}{|c|}{ Kelas Eksperimen } & \multicolumn{2}{c|}{ Kelas Kontrol } \\
\cline { 2 - 5 } & $\begin{array}{c}\text { Kemampuan } \\
\text { Berpikir Kritis }\end{array}$ & Hasil Belajar & $\begin{array}{c}\text { Kemampuan } \\
\text { Berpikir Kritis }\end{array}$ & Hasil Belajar \\
\hline Rerata (mean) & 77,08 & 86,25 & 68,75 & 77 \\
\hline Median & 74,9 & 93,4 & 68,5 & 79,07 \\
\hline Modus & 95 & 100 & 75 & 90 \\
\hline Variansi & 178 & 252,7 & 14 & 16 \\
\hline Standar Deviasi & 13 & 15,8 & 100 & 100 \\
\hline XMaksimum & 100 & 100 & 45 & 50 \\
\hline XMinimum & 55 & 40 & & \\
\hline
\end{tabular}

Sumber dianalisis menggunakan perhitungan manual

Dari abel di atas diperoleh nilai kategori nilai pada setiap kelas yaitu nilai yang berada pada kategori tinggi pada variabel kemampuan berpikir kritis dan hasil belajar siswa sebagai berikut: 


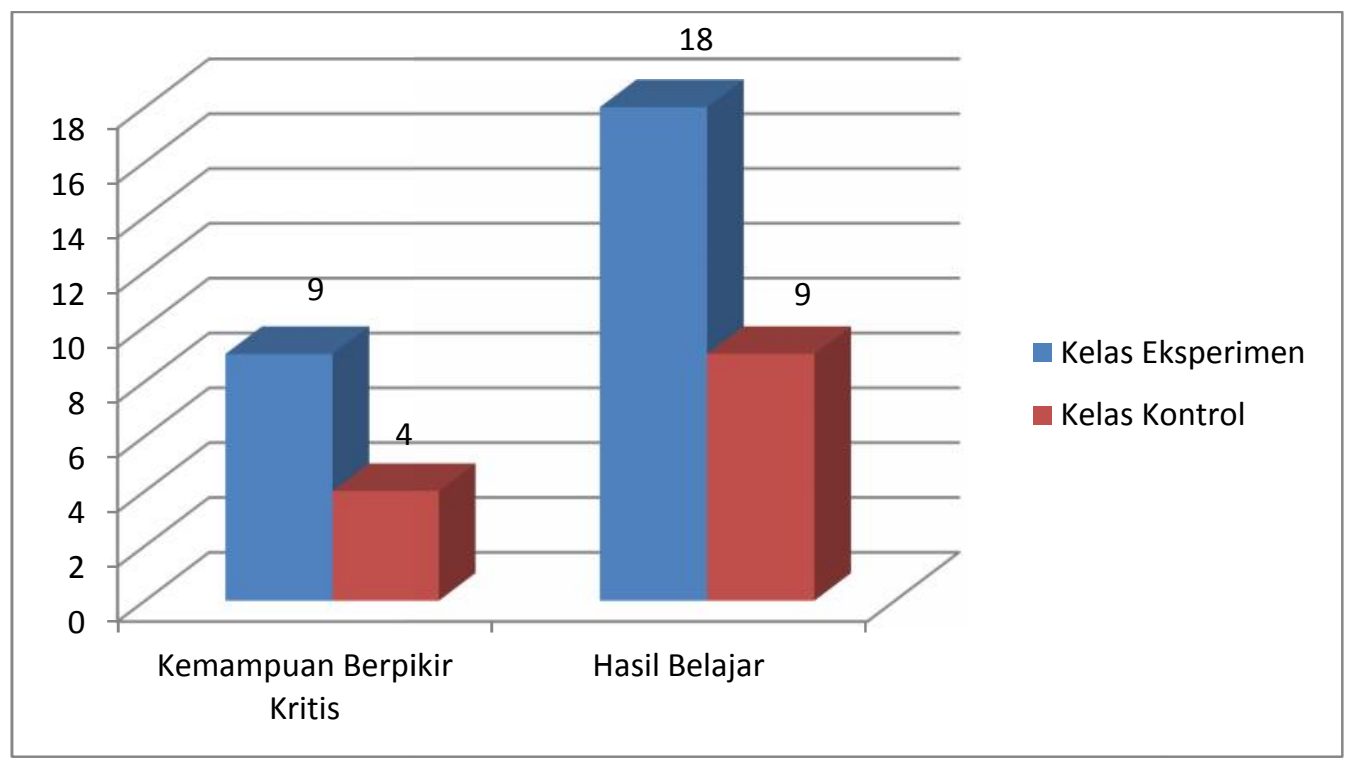

Gambar 1. Nilai Kategori Tinggi pada Variabel Kemampuan Berpikir Kritis dan Hasil Belajar

Pada gambar 1, Nilai kemampuan berpikir kritis siswa dengan kategori tinggi pada kelas pada kelas eksperimen terdapat 9 siswa (37,5\%). Sedangkan pada kelas kontrol terdapat 4 siswa (17\%). Nilai hasil belajar siswa pada kategori tinggi pada kelas eksperimen terdapat 18 siswa (75\%) sedangkan pada kelas kontrol terdapat 9 siswa $(37,5 \%)$. Hal tersebut dapat diartikan bahwa nilai kemampuan berpikir kritis dan hasil belajar siswa yang menggunakan model PBL berbasis multimedia lebih tinggi daripada siswa yang hanya menggunakan model konvensional.

\section{Uji Persyaratan Analisis}

Sebelum pengujian hipotesis, terlebih dahulu dilakukan uji prasyarat, yaitu; uji normalitas lilliefors dan uji $F$ untuk pengujian homogenitas variuans, adalah sebagai berikut:

\section{a. Pengujian Normalitas Data}

Tabel 2. Hasil Pengujian Normalitas Data Hasil Penelitian

\begin{tabular}{clccc}
\hline & \multicolumn{1}{c}{ Kelompok } & $\mathbf{L}_{\text {hitung }}$ & $\mathbf{L}_{\text {tabel }}$ & Kesimpulan \\
\hline \multirow{2}{*}{ Eksperimen } & Kemampuan Berpikir Kritis $\left(\mathrm{T}_{\mathrm{E} 1}\right)$ & 0,1437 & 0,1766 & Normal \\
\cline { 2 - 5 } & Hasil Belajar $\left(\mathrm{T}_{\mathrm{E} 2}\right)$ & 0,1636 & 0,1766 & Normal \\
\hline \multirow{2}{*}{ Kontrol } & Kemampuan Berpikir Kritis $\left(\mathrm{T}_{\mathrm{K} 1}\right)$ & 0,1285 & 0,1766 & Normal \\
\cline { 2 - 5 } & Hasil Belajar $\left(\mathrm{T}_{\mathrm{K} 2}\right)$ & 0,125 & 0,1766 & Normal \\
\hline
\end{tabular}

Sumber Perhitungan Menggunakan Aplikasi Microssoft Exel 2010

Kriteria:

Jika $\mathrm{L}_{\text {hitung }}<\mathrm{L}_{\text {tabel }}$ artinya berdistribusi normal

Jika $\mathrm{L}_{\text {hitung }}>\mathrm{L}_{\text {tabel }}$ artinya berdistribusi tidak normal

\section{b. Pengujian Homogenitas Data}

Tabel 3. Hasil Pengujian Homogenitas Data Hasil Penelitian

\begin{tabular}{|c|c|c|c|c|}
\hline Kelompok Variansi & & $\mathbf{F}_{\text {hitung }}$ & $\mathbf{F}_{\text {tabel }}$ & Kesimpulan \\
\hline Kemampuan Berpikir Kritis & $\mathrm{T}_{\mathrm{E} 1} \& \mathrm{~T}_{\mathrm{K} 1}$ & 1,04 & 3,47 & Homogen \\
\hline Hasil Belajar & $\mathrm{T}_{\mathrm{E} 2} \& \mathrm{~T}_{\mathrm{K} 2}$ & 1,01 & 3,47 & Homogen \\
\hline
\end{tabular}

Kriteria:

Jika $\mathrm{F}_{\text {hitung }}<\mathrm{F}_{\text {tabel }}$ artinya data menyebar secara homogen

Jika $F_{\text {hitung }}>F_{\text {tabel }}$ artinya data menyebar secara tidak homogen

3. Hipotesis Kemampuan Berpikir Kritis dan Hasil Belajar

Tabel 4. Hasil Pengujian Hipotesis Data Hasil Penelitian

\begin{tabular}{ccccc}
\hline Kelompok & & $\mathbf{t}_{\text {hitung }}$ & $\mathbf{t}_{\text {tabel }}$ & \multicolumn{2}{c}{ Keterangan } \\
\hline Kemampuan Berpikir Kritis & $\mathrm{T}_{\mathrm{E} 1} \& \mathrm{~T}_{\mathrm{K} 1}$ & 9,9 & 1,67 & $\mathrm{H}_{\mathrm{o}}$ ditolak \\
\hline Hasil Belajar & $\mathrm{T}_{\mathrm{E} 2} \& \mathrm{~T}_{\mathrm{K} 2}$ & 10,2 & 1,67 & $\mathrm{H}_{\mathrm{o}}$ ditolak \\
\hline
\end{tabular}

Kriteria: 
Taraf signifikansi $(\alpha)=0,05 t_{(1-a)(24+24-2)}$

Jika $\mathrm{t}_{\text {hitung }}<\mathrm{t}_{\text {tabel }}$ maka H0 diterima

jika $t_{\text {hitung }}>\mathrm{t}_{\text {tabel }} \mathrm{HO}$ ditolak

Berdasarkan kriteria tersebut diperoleh hasil bahwa $\mathrm{H}_{0}$ ditolak pada kelompok kemampuan berpikir kritis pada taraf signifikansi $5 \% \mathrm{t}_{(1-\alpha)(24+24-2)}=1,67$ yaitu $\mathrm{t}_{\text {hitung }}>\mathrm{t}_{\text {tabel }}=9,9>1,67$ Hal tersebut menunjukan bahwa terdapat perbedaan kemampuan berpikir kritis siswa yang menggunakan model PBL berbasis multimedia dan model konvensional dan diperoleh hasil bahwa $\mathrm{H}_{0}$ ditolak pada kelompok hasil belajar pada taraf signifikansi $5 \% \mathrm{t}_{(1-\alpha)(24+24-2)}=1,67$ yaitu $\mathrm{t}_{\text {hitung }}>\mathrm{t}_{\text {tabel }}=10,2>1,67$ Hal tersebut menunjukan bahwa terdapat perbedaan hasil belajar siswa yang menggunakan model PBL berbasis multimedia dan model konvensional.

\section{PEMBAHASAN}

Berdasarkan hasil penelitian yang dilakukan pada materi tekanan zat meunjukan bahwa nilai rata-rata kemampuan berpikir kritis siswa yang menggunakan model PBL berbasis multimedia sebesar 77,08, sementara nilai rata-rata kemampuan berpikir kritis siswa yang hanya menggunakan model konvensional hanya sebesar 68,8 sehingga diperoleh selisih nilai sebesar 8,28. Nilai tersebut menunjukkan bahwa dengan menggunakan model PBL memiliki pengaruh dalam meningkatkan kemampuan berpikir kritis. Hal tersebut dapat dilihat dari tabel dimana kategori sangat tinggi pada kelas eksperimen sebanyak 9 siswa dengan nilai di atas 85,5 berbeda dengan kelas kontrol yaitu sebanyak 4 siswa dengan nilai di atas 81,5. Hal tersebut dapat diartikan bahwa nilai kemampuan berpikir kritis siswa yang menggunakan model PBL berbasis multimedia lebih tinggi daripada siswa yang hanya menggunakan model konvensional. Hasil tersebut didukung dengan penelitian terdahulu yang menyatakan bahwa penerapan model PBL dapat meningkatkan keterampilan berpikir kreatif siswa pada konsep Elastisitas (Rahayu, dkk., 2016).

Kemudian nilai rata-rata hasil belajar siswa yang menggunakan model PBL berbasis multimedia sebesar 86,25, sementara nilai rata-rata hasil belajar siswa yang hanya menggunakan model konvensional hanya sebesar 77. Hal tersebut dapat dilihat dari tabel 1 dimana kategori hasil belajar sangat tinggi pada kelas eksperimen sebanyak 18 siswa dengan nilai di atas 80 dan kategori sangat tinggi pada kelas kontrol sebanyak 9 siswa dengan nilai di atas 83. Nilai tersebut menunjukan bahwa penggunaan model PBL berbasis multimedia sangat berpengaruh terhadap kemampuan berpikir kritis dan hasil belajar siswa. Hasil penelitianini tidak jauh berbeda dengan penelitian Ambarwati yang menyatakan bahwa kelas problem based learning lebih efektif untuk diterapkan dalam proses pembelajaran, hal tersebut juga dapat dilihat dari nilai rata - rata kognitif siswa yang diperoleh dari hasil postest siswa yang menunjukan nilai lebih tinggi dari pada hanya menggunakan model ceramah (Ambarwati, 2017). Sehingga dengan demikian penggunaan model PBL berbasis Multimedia dalam proses pembelajaran dapat dikatakan memberikan pengaruh yang lebih baik yang lebih baik terhadap hasil belajar siswa.

Hasil uji hipotesis perbedaan kemampuan berpikir kritis siswa pada kelas yang menggunakan model pbl berbasis multimedia dan kelas yang menggunakan model konvensional terdapat perbedaan yang signifikan diperoleh nilai $t_{\text {hitung }}=9,9$ dan $t_{\text {tabel }}=1,67$ dengan $\mathrm{dk}=46$ dan taraf signifikansi $\alpha=0,05$ sehingga terlihat bahwa $t_{\text {hitung }}>t_{\text {tabel }}$ yaitu 9,9 $>1,67$. Hal ini berarti bahwa kemampuan berpikir kritis siswa yang menggunakan model PBL berasis multimedia lebih tinggi dibandingkan dengan kemampuan berpikir kritis siswa yang menggunakan model konvensional. Hal tersebut juga dinyatakan dalam sebuah penelitian terdahulu yaitu aktivitas pembelajaran menggunakan model problem based lerning dapat mendorong pola pikir kreatif, aktif dan partisipatif dalam memecahkan masalah karena siswa dapat secara leluasa mengembangkan kemampuan berpikirnya (Wulandari, 2018). Hal serupa dikemukakan oleh Kurnia yang menyatakan Kemampuan berpikir kritis merupakan bagian dari krmampuan berpikir matematis yang perlu dimiliki oleh setiap siswa dalam menghadapi berbagai permasalahan. Bila berpikir kritis dikembangkan, seseorang akan cenderung untuk mencari kebenaran, berpikir terbuka dan toleran terhadap ide-ide baru, dapat menganalisis masalah dengan baik, berpikir secara sistematis, penuh rasa ingin tahu, dewasa dalam berpikir, dan dapat berpikir secara mandiri. Siswa yang berpikir kritis akan menjadikan penalaran sebagai landasan berpikir, berani mengambil keputusan dan konsisten dengan keputusan tersebut (Kurnia, 2014). Kemampuan berpikir kritis peserta didik yang diberikan perlakuan model PBL berbasis multimedia dan model konvensional adalah berbeda secara signifikan. Peserta didik yang menggunakan model PBL memiliki kemampuan berpikir kritis yang lebih tinggi dibandingkan dengan kemampuan berpikir kritis siswa yang hanya menggunakan model konvensional. Hasil penelitian ini memberikan pemahaman bahwa pembelajaran IPA dengan menggunakan model PBL berbasis multimedia memancing kemampuan berpikir kritis siswa dikarenakan jelasnya pembelajaran yang diberikan dengan media yang memadai sehingga ketuntasan belajar pada kelas eksperimen lebih tinggi dibandingkan kelas kontrol karena model PBL telah mampu memberi pemahaman siswa secara komprehensif dengan didasari permasalahan sehari-hari dan cara penyelesaiannya. Hal senada juga diungkapkan oleh (Kono, dkk., 2016) bahwa penerapan model PBL yang dilakukan dengan memperhitungkan keterampilan berpikir kritis siswa tetap berpengaruh terhadap penguasann konsep siswa dengan peningkatan rata-rata 98,06\%, artinya penerapan model PBL tetap akan memberikan pengaruh dalam meningkatkan penguasan konsep siswa tentang biologi. Dengan demikian 
model PBL berbasis multimedia lebih efektif digunakan untuk membantu proses bembelajaran IPA dalam meningkatkan kemampuan berpikir kritis siswa dibandingkan dengan pembelajaran konvensional.

Hasil belajar siswa yang diberikan perlakuan model PBL berbasis multimedia pada kelas eksperimen memiliki perbedaan pengaruh secara signifikan dengan hasil belajar peserta didik yang hanya diberikan perlakuan model konvensional yaitu pada kelas kontrol. Berdasarkan uji hipotesis diperoleh nilai $t_{\text {hitung }}=10,2$ dan $\mathrm{t}_{\text {tabel }}=1,67$ dengan $\mathrm{dk}=46$ dan taraf signifikansi $\alpha=0,05$ sehingga terlihat bahwa $\mathrm{t}_{\text {hitung }}>\mathrm{t}_{\text {tabel }} 10,2>1,67$. Hal ini berarti bahwa hasil belajar siswa yang menggunakan model PBL berasis multimedia lebih tinggi dibandingkan dengan hasil belajar siswa yang menggunakan model konvensional. Hal tersebut didukung oleh teori yang menyatakan bahwa dalam hal sarana belajar, kooperatif menekankan bahwa peranan utama dalam dalam kegiatan belajar adalah aktivitas siswa dalam mengkonstruksi pengetahuannya sendiri. Dengan ini konsep akan tertanam lebih kuat dalam benak siswa sehingga hasil belajar yang diperoleh siswa akan optimal.(Siregar, 2014). Model PBL memiliki tiga tujuan belajar yaitu meningkatkan pemahaman tentang proses-proses yang terlibat dalam pembelajaran berbasis masalah, megembangkan pembelajaran mandiri siswa dan mendapatkan pemahaman mendalam tentang topik-topik yang spesifik. Penerapan model pembelajaran ini untuk menjadikan siswa memiliki pengetahuan dan kemampuan berpikir kritis dalam hal mencari solusi terhadap permasalahan yang diberikan dalam proses pembelajaran. Setidaknya tiga kemampuan siswa dapat dikembangkan dalam hal ini yaitu kemampuan untuk melakukan investigasi, kemampuan berpartisipasi dan berkomunikasi (Nurmala, 2016). Salah satu tujuan dari pembelajaran IPA yaitu berpikir secara kritis, rasional dan teliti dalam pembelajaran IPA dapat tercapai melalui model problrm based learning karna terbukti berpengaruh dapat meningkatkan hasil belajar dan kemampuan berpikir kritis siswa. Karena kemampuan berpikir kritis sangat diperlukan untuk menunjang pengetahuan yang telah dimiliki.

\section{KESIMPULAN}

Berdasarkan hasil penelitian dan pembahasan yang telah diuraikan sebelumnya, maka dapat diperoleh kesimpulan, bahwa: Terdapat perbedaan kemampuan berpikir kritis siswa yang menggunakan model PBL berasis multimedia dan kemampuan berpikir kritis siswa yang menggunakan model konvensional, dimana nilai $t_{\text {hitung }} 9,9>t_{\text {tabel }} 1,67$ serta terdapat perbedaan hasil belajar siswa yang menggunakan model PBL berasis multimedia dan hasil belajar siswa yang menggunakan model konvensional, dimana nilai $t_{\text {hitung }} 10,2>t_{\text {tabel }} 1,67$.

\section{DAFTAR PUSTAKA}

Ambarwati, S. (2015). Perbandingan Hasil Belajar Biologi Menggunakan Model Pembelajaran Problem Based Learning Dan Problem Solving Kelas VII SMP Muhammadiyah 5 Surakarta Tahun Ajaran 2014 / 2015. (Universitas Muhamadiyah Surakarta).

Arikunto, S. (2012). Dasar-Dasar Evaluasi Pendidikan. Edisi 2. Jakarta: Bumi Aksara.

Astuti, R. dkk.(2012). "Pembelajaran Ipa Dengan Pendekatan Keterampilan Proses Sains Menggunakan Metode Eksperimen Bebas Termodifikasi Dan Eksperimen Terbimbing Ditinjau Dari Sikap Ilmiah Dan Motivasi Belajar Siswa", Jurnal Inkuiri, 1, hal. 51

Bidang DIKBUD. (2013). Undang-Undang Sistem Pendidikan Nasional. Jakarta.

Djemari, Mardapi. (2010) Tekhnik Penyusunan Instrumen Tes Dan Nontes. Yogyakarta: Mitra Cendikia Press.

E., Siregar. (2014). Teori Belajar dan Pembeajaran. Bogor: Ghalia Indonesia.

Kono, Rahmad, dkk. (2016). Pengaruh Model Problem Based Learning (PBL) Terhadap Pemahaman Konsep Biologi dan Keterampilan Berpikir Kritis Siswa Tentang Ekosistem dan Lingkungan Di Kelas X SMA Negeri 1 Sigi. Jurnal Sains dan Teknologi tadulako, vol. 5, no. 1, hlm. 28-31.

Kurnia. (2014). Implementasi Brain Based Learning Untuk Meningkatkan Kemampuan Koneksi Dan Berpikir Kritis Serta Motivasi Belajar Siswa. Jurnal Pendidikan UNISKA, Vol. 2, No. 1.

Nurmala. (2016). Upaya Meningkatkan Hasil Belajar IPS Melalui Penerapan Model Pembelajaran Numbered Head Together (NHT) Siswa Kelas IX.5 SMP Negeri 2 Metro Tahun Pelajaran 2012/2013. Jurnal Pendidikan Ekonomi UM Metro. Vol.4. No.1, hal. 67

Poedjiadi, Anna. (2010). Sains Teknologi Masyarakat. Bandung: PT. Remaja Rosdakarya.

Rahayu, Dkk. (2016) Pengaruh Model Problem Based Learning Terhadap Berpikir Kritis Dan Hasil Belajar Elastisitas Siswa Kelas XI SMA Negeri 7 Banda Aceh. Jurnal Pendidikan Sains Indonesia, Vol.04, No.02, h. 105-116.

Rusman. (2013). Model-Model Pembelajaran. Jakarta: Raja Grafindo Persada.

Sugiyono. (2017). Statistika Untuk Penelitian. Bandung:Alfabeta. 
Wisudawati dan Sulistyowati. (2015). Metodelogi Pembelajaran IPA. Jakarta: Bumi Aksara. h. 24.

Wulandari, T. (2018). Pengaruh Model Pembelajaran Problem Based Learning Terhadap Hasil Belajar Matematika Siswa Kelas V SDN Nanggulan, Universias Sanata Darma Yogyakarta. 